Article

\title{
Coproduction as an Approach to Technology-Mediated Citizen Participation in Emergency Management
}

\author{
Paloma Díaz ${ }^{1, *}$, John M. Carroll ${ }^{2}$ and Ignacio Aedo ${ }^{2}$ \\ 1 Computer Science Department, Universidad Carlos III de Madrid, Leganés 28911, Spain \\ 2 College of Information Sciences and Technology, The Pennsylvania State University, University Park, \\ PA 16802, USA; jcarroll@ist.psu.edu (J.M.C.); aedo@ia.uc3m.es (I.A.) \\ * Correspondence: pdp@inf.uc3m.es; Tel: +34-916249456
}

Academic Editors: Genoveffa Tortora and Giuliana Vitiello

Received: 6 June 2016; Accepted: 29 July 2016; Published: 10 August 2016

\begin{abstract}
Social and mobile computing open up new possibilities for integrating citizens' information, knowledge, and social capital in emergency management (EM). This participation can improve the capacity of local agencies to respond to unexpected events by involving citizens not only as first line informants, but also as first responders. This participation could contribute to build resilient communities aware of the risks they are threatened by and able to mobilize their social capital to cope with them and, in turn, decrease the impact of threats and hazards. However for this participation to be possible organizations in charge of EM need to realize that involving citizens does not interfere with their protocols and that citizens are a valuable asset that can contribute to the EM process with specific skills and capabilities. In this paper we discuss the design challenges of using social and mobile computing to move to a more participatory EM process that starts by empowering both citizens and organizations in a coproduction service envisioned as a partnership effort. As an example, we describe a case study of a participatory design approach that involved professional EM workers and decision makers in an effort to understand the challenges of using technology-based solutions to integrate citizen skills and capabilities in their operation protocols. The case study made it possible to identify specific roles that citizens might play in a crisis or disaster and to envision scenarios were technologies could be used to integrate their skills into the EM process. In this way the paper contributes to the roles and the scenarios of theory-building about coproduction in EM services.
\end{abstract}

Keywords: citizen participation; coproduction; emergency management; empowering technologies; social and mobile computing

\section{Introduction}

The combination of social and mobile computing has raised many expectations about the capability of these technologies to promote a more active participation of citizens in different areas of the public sphere on the assumption that they offer a powerful and widely available communication and collaboration channel that can be used for self-reporting, self-organizing, and supporting remote participation in events and tasks [1]. The possibility of sharing and collaborating without time and space constraints can been exploited to improve government action and situational awareness, not only in terms of having a deeper understanding of the situation and its possible evolution as defined by Endsley [2], but also enhancing awareness about the citizens' social capital, and their knowledge and skills, or what is sometimes called the wisdom of the crowd. Indeed, technologies like web sites, wikis and social networks are used with more or less impact in many governmental agencies to promote a more transparent administration and, at the same time, try to engage citizens in civic 
issues like city planning and e-government $[1,3]$. Disaster and emergency management is another domain where the use of social and mobile computing might make it possible to take profit from that wisdom of the crowd, taking into account that citizens are the first responders in any catastrophic situation affecting their community [4]. Map-based and social technologies have been proposed to support citizen journalism and communications citizen-to-citizen and government-to-citizen [5-8]. Whenever a crisis happens, citizens post information on social networks, like Twitter or Facebook, and organize groups to express emotions or to share concerns [5,6]. For example, in the European floods of 2013, Ludwig et al. report the creation of 157 Facebook groups in Germany related with the event [9]. Map-based web sites, like Ushaidi or OpenStreetMap, are spontaneously used by citizens to share geolocated crisis information $[7,10,11]$. However, how this crowd intelligence can be further integrated into the decision-making process of agencies is still an open question [5,9], since professional emergency managers and decision-makers need to rely upon timely and accurate information and citizen-generated content might not fit these criteria $[5,9,12,13]$.

In this work we focus on the citizen-to-government interaction with a view to exploring the role that social and mobile computing might play to turn citizen participation into a valuable asset when emergency management (EM henceforth) is conceived as a coproduction service. The term coproduction was introduced by Elinor Ostrom to refer to "the process through which inputs used to produce a good or service are contributed by individuals who are not in the same organization" [14]. Envisaging $\mathrm{EM}$ as a coproduction service implies looking for ways to integrate participants who are not part of the EM corps and agencies (EMA henceforth) into the different phases of the EM process, namely, preparation, response, mitigation, and recovery [15]. Currently, agents, like non-governmental agencies or volunteers, already participate actively as external partners, but the role of citizens is still quite limited and rarely coordinated with the action of EMAs [8] that tend to adopt a command-and-control structure that facilitates accountable decision-making [16]. Panic or disorganization among citizens, which are usually claimed by EMAs to apply command-and-control policies, rarely happen and do not affect to the community and individual capabilities to mobilize their social capital [17]. Moreover, with the advent of social and mobile computing, citizens are also developing a digital social capital [1], defined as the process of building online communities who pursue common goals and can be mobilized to act more efficiently. The existence of this digital social capital makes it possible to involve also citizens who are not affected by the crisis [8,11]. For example, when the government of Belgium imposed a security lockdown on Brussels on 21 November 2015 due to a potential threat of terrorist attacks, the police asked the population to not share information about their activities in social networks. Citizens started to spontaneously use the hashtag \#BrusselsLockdown to post pictures of cats and this practice became a trending topic not only in Belgium, as citizens from other countries joined this initiative to try to avoid terrorist getting access strategic information through social networks.

Citizens have motivations to co-produce in an emergency situation, whether for sheer rational egoism [18] or due to their social connectedness with the affected community or to an altruistic behavior motivated by sympathy with the victims [17]. From the government point of view, service coproduction should not be regarded as an option but as a way to improve public services and make them more sustainable by focusing not only of what people need but also on what people can do [19]. Indeed, Ostrom introduced the concept of coproduction when analyzing the case of the Chicago police, whose decision to move from foot to car patrols derived in an increase in the crime rate due to the lack of contact with the neighbors so that they did not take profit from the citizens skills and informal knowledge of the street. As posited by Jane Jacobs in her influential book "The Death and Life of Great American Cities" [20], streets are safer when the neighbors live in them and take an active role keeping an eye on what happens on them. This kind of asset cannot be ignored by the service providers, but needs to be integrated in a partnership effort, that is, into a coproduction service. Coproduction services have been promoted in areas like health, education, or urban planning [18,19], but they could also be applied to EM in order to incorporate citizens as valuable resources and not only as recipients of help. However, for that to be possible EMAS need to identify ways to involve citizens 
without interfering with their protocols and responsibilities. The work reported on this paper uses the coproduction concept as the lens through which contribute to theory building about participatory EM services envisioned as a partnership relationship with citizens. In Section 2, we review the conceptual foundations to move to a coproduction service in EM. Section 3 introduces a design case study that, after analyzing the current situation and expectations of EM professionals about citizen participation through empirical studies with EM professionals, shaped the crowd of citizens as a heterogeneous set of roles whose skills and capacities could contribute to move to a coproductive EM. The identification of such roles, including sensors, nodes, and agents, was done through a participatory process based on focus groups with different EMAs. Such roles helped to identify scenarios where ubiquitous and social computing could make EM participatory, and yet appropriate from the point of view of EMAs. Roles contribute to theory-building on the implementation of EM as a coproduction service by providing an abstract mechanism to envision the skills and capabilities citizens can bring to make EM more participatory, yet efficient.

\section{Conceptual Foundations: From Community-Based EM to Coproduction}

EM is a process composed by four phases: mitigation, preparedness, response, and recovery. Mitigation encompasses all the activities to be done when a risk has been detected; preparedness is related with developing response plans and training activities; the response phase deals with providing aid and assistance to minimize damages; and, finally recovery is concerned with supporting the early phases of returning to normal life [15]. Information and communication technologies can support an active role of citizens in each of these phases by treating them as intelligent agents in the pursuit of achieving resilient communities able to recover and function normally in the aftermath of disasters. For instance, citizens can track alerts and the evolution of hazards, coordinate and collaborate in the local response, support community preparation for specific hazards, or provide information and knowledge on how to recover from a disaster [7]. They can act as intelligent sensors that provide valuable feedback on the situation since they are familiar with the area and they are increasingly equipped with technologies like smartphones that empower them to capture information $[9,10]$. Mechanisms, such as social networks, blogs, or micro-blogging, are forms of viral communication that have already given a voice to citizens in major disasters $[5,6,21]$. However, as pinpointed by Benkler in his work on the limitations of digital social networks as democratizing tools, "when everybody can speak, the central point of failure becomes the capacity to be heard" [22]. In fact, EMAs are aware of the important role social networks play in their communication with citizens but also of the limitations to properly manage this huge amount of data [23].

In any case, conceiving technological tools only as communication channels, whether unidirectional (that is organizations informing citizens and citizen journalism) or bidirectional (that is citizens contacting organizations and getting feedback from them), is a very limited interpretation of citizen participation. EM is not only about communication, it is about collaboration; it is about information and knowledge sharing and integration, and about coordinated decision-making and action [16]. The Web 2.0 is not only about communicating in a viral way but it is also about enabling collaboration $[1,3,22]$. Citizens can engage in more activities by means of local community response grids [8] or using social computing applications. For example, very simple social tools like Google Spreadsheets or Forms offered a quick, cheap and accessible mechanism to coordinate the two thousand people who volunteered to help $60 \mathrm{~min}$ after the Boston Marathon bombing [24]. Indeed FEMA defines emergency managements as "the managerial function charged with creating a framework within which communities reduce vulnerability to hazards and cope with disasters" [25]. This definition shifts the goal of EMAs from mere incident responders to recognize their responsibility on supporting the creation of resilient communities that are defined as groups of people that have developed a set of capacities as a group, not only as individuals, to recover effectively from disasters [26]. Such capacities are what is usually called in the literature social capital, defined as the resources that are available to individuals through their social networks. It has been empirically demonstrated that communities with stronger 
social capital recover better from disasters than communities with looser social ties and, in turn, they become more resilient $[27,28]$. Research on the role of the communities' social capital in EM advocates to move towards a community-level EM [17] assuming that "emergency management capacity is built from the ground up" [16]. Table 1 summarizes two different perspectives of EM as described in [16]: the classical top-down approach initiated and led by organizations versus a community-level approach where EM is built on the basis of social capital as a basic resource to cope with disasters. In the table each cell specifies the goals that are pursued from each perspective at each of the phases of EM. For instance, in the classical top-down approach, during the preparation phase the governmental agencies are in charge of designing plans and train first responders to be ready to act in case of an event, whilst in a participatory perspective what has to be done is to strengthen existing social structures and connections so that they can be mobilized in case of an event [28]. Whilst the first one strongly relies on the role of professional EM workers, the second one tries to capitalize or reinforce the resources that already exist or might exist in a community of citizens. In this case, citizens are not only reactive to the crisis; they can also be proactive and be prepared to be less vulnerable.

Table 1. Different perspectives of the EM (emergency management) phases.

\begin{tabular}{|c|c|c|}
\hline EM Phases & Top-Down Hierarchical EM [15] & Community-Level EM [28] \\
\hline Mitigation & $\begin{array}{l}\text { Deciding what to do when a risk has } \\
\text { been determined and implementing a } \\
\text { risk reduction program }\end{array}$ & $\begin{array}{l}\text { Reducing the vulnerability of } \\
\text { social capital }\end{array}$ \\
\hline Preparedness & $\begin{array}{l}\text { Developing a response plan and } \\
\text { training first responders }\end{array}$ & Enhancement of social capital \\
\hline Response & $\begin{array}{l}\text { Providing emergency aid } \\
\text { and assistance }\end{array}$ & $\begin{array}{l}\text { Utilization of social capital in problematic } \\
\text { situations, evoking resilience }\end{array}$ \\
\hline Recovery & $\begin{array}{l}\text { Provide support until the community } \\
\text { returns to normal }\end{array}$ & $\begin{array}{l}\text { Reestablishment of social capital, } \\
\text { leveraging resilience }\end{array}$ \\
\hline
\end{tabular}

In this work we assume the Putnam's conception of social capital that highlights the role of civic engagement in creating good government by promoting coordinated action [29] with a view of conceiving EM as a coproduction service. Coproduction is way to provide public services in partnership with citizens and by positing that EM should be envisioned as a coproduction service we are recognizing that citizen participation is not an option, but a requirement, to adhere to FEMA's definition of the of role of EMAs previously introduced [25]. Indeed it has been demonstrated that successful experiences in coproduction increases civic engagement in other community activities, and hence contributes to develop social capital [30].

According to Ostrom, coproduction faces three basic challenges: existence of social capital outside the organization, existence of social capital within the organization, and coordination among citizens and the organizations [14]. The existence of social capital and digital social capital has been already discussed in the literature $[1,3,17,27,28]$. In this work we will focus on how social and mobile computing can contribute to improve coordination among citizens and organizations taking into account the perspective of the organizations, EMAs, which are the ones who hold the social responsibility on EM. In particular, we aim at understanding how technological tools can substantively empower both citizens and institutions to act in an integrated and coordinated coproduction service. In the next section we describe a design case use that based on a participatory design process where EMA workers and decisions makers perceptions and ideas were used to envision social and mobile computing technologies that could eventually help to move the EM process towards a coproduction service.

\section{Design Case Study: The Participative Roles of Citizens in EM}

Technologies that promote effective and reliable collaboration in EM among different stakeholders, including first responders, decision- and policy-makers, volunteers, and citizens, are sociotechnical 
systems; their design focuses on implications on people and the work environment, that is, on the social structures and behaviors that are affected by technology [31]. In our case, to use technology to empower organizations and citizens it is necessary to understand the capabilities citizens can provide and how these capabilities can be aligned with the goals and needs of EMAs. With that purpose, we describe in this section a design case study that shows how citizen roles and capabilities were identified in the context of a project aimed at using social and mobile computing to increase citizen participation in EM [32]. A design case study is a research approach that consists of empirically analyzing the existing practices in a specific field of application to design technological artifacts that cope with the findings of such analysis [9,33]. As described in section 3.1, our design case study started by analyzing the current practices on the integration of technology-mediated citizen participation in EMAs. Two empirical studies with professional EM workers and decision-makers helped to understand the current situation and perception about citizen participation. They also helped to find out opportunities and challenges where technology could support a coproduction EM service. As posited by Alford, an important step in devising coproduction services is to clearly shape both terms "co" and "production " [18], that is, who are the coproducers or types of actors involved in the process, and what is it that is going to be coproduced? Thus, an important goal of the design process in the case study was to identify the potential roles citizens might play as EM coproducers (section 3.2) and the scenarios where technology might help to integrate their potential contributions with the EMAs working protocols and tools (section 3.3). Concerning the type of production expected, Linders [3] identifies three types of coproduction: citizen sourcing, when citizens contribute to make government more responsive and effective; government as a platform, when the government ICT infrastructure is made available to citizens to help them take decisions; and do it yourself government, when citizens self-organize themselves with little or no government intervention. In this work we will study EM as a citizen-sourcing coproduction process.

\subsection{Empirical Studies with Emergency Workers and Decision-Makers: Understanding Their Perspective on Technology-Mediated Citizen Participation}

To understand the perception of EMAs about the use of social and mobile computing to integrate citizens in their practice, two empirical studies were carried out with professionals of different agencies. The first one was performed on 2011 and was aimed at finding out the main challenges that EMAs had to integrate social networks in their daily practices. One year later the use of social technologies was becoming almost pervasive in most crisis situations for communication purposes, so we conducted a new study to explore ways in which greater levels of citizen participation could be integrated thanks to the use of social computing technologies in EM. The next sections describe, briefly, both studies, which are fully documented in [34-36].

\subsubsection{First Study: The Challenges of Integrating Social Computing in EM}

In August 2011 a study involving 36 emergency workers and decision-makers from British Columbia and Washington State was carried out in the city of Vancouver as part of a series of workshops about the use of social networks in EM organized by the City of Richmond and Simon Fraser University. The goal of the study was to find out the main challenges EMAs faced to integrate social computing within their working protocols. Participants belonged to very different agencies, with different sizes and resources what guaranteed a varied perception of the real situation. After a short introduction and discussion on the use of social media in EM, participants filled a questionnaire made up of closed questions that explored the utility and potential problems of using them in their daily practice. A detailed description of the study and its findings can be found in [34] but, as a summary, there were three main obstacles identified: a) they had to make sense of a huge quantity of messages, not all of them equally informative and reliable, since most citizens lack the technical knowledge required to analyze the situation and provide an accurate picture useful for the professionals; $b$ ) they had to give an immediate answer to the messages generated by the citizens, for which not all of the 
agencies had enough resources; and c) they had to deal with a) and b) whilst being efficient in their response. During the workshop discussions participants highlighted the need for democratizing EM by involving citizens, but the results of the survey also confirmed what the literature consistently points out about lack of trust and the quality of the information generated by citizens $[1,7,9]$. A second questionnaire was filled after a short presentation of a specific software prototype called remerWeb that was used to illustrate with a real example how to integrate a community of volunteers into the EM process as a first step to move to a coproduction service. In this case, the closed questions explored how the prototype would improve communication, coordination, and integration and also the technologies and approaches that could be used to engage communities in EM. As reported in [35], the main barriers identified were about trust and reliability, information processing and integrity, and interaction support. We will revisit these issues in the findings of both studies. We will revisit these issues in the findings of both studies.

\subsubsection{Second Study: Understanding the Perception of a More Active Citizen Participation}

The second study was oriented towards analyzing current practices in technology-mediated citizen participation, and it was performed in Spain where the project was aimed at deploying technology. The study was based on a web questionnaire organized in three sections: the first one was about the professional profile of participants; the second section included questions related with current practices involving citizen participation in EM; and, finally, a last section was aimed at exploring how participants envisioned citizen participation in the future and the role ICT technologies might play in such a future. The questionnaire included both closed questions answered using 4-value Likert scales, as well as open questions. Data analysis and findings are thoroughly described in [36]. The web questionnaire was open from April to May 2013. During these two months, several Spanish emergency organizations were invited to participate. Since there was no possible way to reward participants, who were professional, paid workers, coordinators of the EMAs were used as facilitators to invite their workers to take part in the survey. In order to encourage participation two conditions were clearly stated: a) the participation was anonymous and no information, comments or perceptions of workers would be disclosed to their EMAs, b) the study had nothing to do with potential policies to substitute current workers with non-paid volunteers. This last issue raised many concerns, since the survey was being carried out in a period of economic crisis where many public services were suffering serious budget cuts and some participants were afraid that accepting a higher citizen participation would result on having fewer professional workers. At the end 29 professionals took part in the study. They worked for seven different organizations in charge of cities or regions that in total involved more than 3.5 million people.

The main problems identified were basically the same that emerged in the first study and in the literature: the difficulty to trust the information provided by the citizens and the lack of resources to handle large quantities of information generated in social networks. What was more interesting was their perceptions on how to envision citizen participation that was collected through a series of questions aimed at identifying potential citizen roles. In particular, participants explored three potential roles: citizens as mere informants (called sensors), citizens informing and reacting to an event following the instructions of authorities (called reactive sensors), and citizens taking the lead in EM activities (called proactive sensors). The preferred role for the participants was reactive sensors, that is, citizens with an involvement that goes further of just providing information though this would imply in the words of one of the participants "to invest in preparation and training before trusting them".

\subsubsection{Findings of the Empirical Studies}

These two studies made it possible to identify a number of issues that combined with other findings reported in the literature inspired the design of socio-technical systems supporting EM as a coproduction service. We can summarize such findings in three broad categories 
1. EMAs are aware of the necessity of integrating social networks in their daily practice. This is not a new finding; it is a need that has been consistently reported in by scholars and practitioners [23,37]. However, the way to implement this integration taking into account the resources and protocols of EMAs is still an open question. Citizens are using social media to communicate and to create digital social capital, and professional EM workers have to be aware of all the networks and channels that have to be used to communicate important information [17]. According to [23], EMAs apply three strategies in social networks: push, if they are conceived as an additional communication channel; pull, when they are used to engage citizens in other activities like directing them to related web sites or asking them to send specific information; and networking, when they are conceived as an active bidirectional channel with different audiences, including other agencies and actors involved in the EM process. The type of strategy adopted depends on the experience emergency workers have in using social media [23], as well as on the available resources [34]. Indeed, in our first study two barriers that some participants raised were dealing with different social networks and being able to convey effective messages given the limitations of the types of messages that can be broadcasted in social networks like twitter. In any case, as discussed above and as posited by Sherry Arnstein in her participation ladder [38] informing and consultation, which are the kind of participation supported using pull and push tactics, can be regarded as forms of tokenism, a way to give citizens the impression their opinions count but without authorities losing power and control on the situation. To have citizens working as partners in a coproduction service, higher rungs of the ladder need to be climbed, including partnership, power delegation, and citizen power. Technologies, per se, do not offer a panacea to climb the rungs, since there are many issues related with trust and reputation that need to be addressed first [1]. However, social computing is generating a digital social capital that might be integrated as a valuable asset in EM. A participatory design process involving EMAs in the exploration of scenarios and ways to exploit such assets might help to envision applications empowering both citizens and agencies.

2. Trust and information processing are key issues to integrate citizen-generated content within EM practice. Apart from the lack of preparation, one of the main challenges to integrate citizen-generated content to support decision-making processes in EMAs is how to process and respond to huge quantities of messages generated in a very short period of time by people who usually under the stress of experiencing a traumatic experience. As an example, Vieweg et al. identified 6674 potential meaningful tweets out of a collection of 1,986,091 tweets for a period of six days during the Oklahoma grassfires of 2009 [6]. Another issue related with citizen-generated content is the quality of the information in order to support situational awareness and decision-making [9]. It is not only a question of trust and reputation on the information sources, it is also a question of the pertinence and technical quality of the information provided. Disasters are not events but processes that are experienced and, consequently, described in a different ways by different people [39]. Citizens are not experts in emergencies and, therefore, their judgments about the impact of an event or the need of resources might not be accurate for professionals who fear to lose efficiency, as well as control, if they depend on the information provided by citizens. In many cases, filtering out the information generated in social networks is delegated to humans. In particular, most EMAs work with their own VOST (Virtual Operations Support Teams). VOST are groups of trusted people, usually recruited among volunteers, who help to detect hoaxes as well as relevant information. It originated in USA in 2011 and now has spread to many countries and regions. They usually have a team leader who is in contact with the EMA managers in their area of influence so they can have a more fluid communication. Technologies, like data mining and visualization, have been also used in research prototypes to organize this huge quantity of information into more manageable sets of data with a view to help EM operators make sense of the situation. For instance, in [9] authors develop an algorithm to automatically derive the quality of data generated in twitter. In [40] the use of ontologies is 
proposed to generate semantic visualizations that categorize tweets according to meaningful concepts in EM.

Our participants did not value very highly the utility of technology to support crowd intelligence processes. Given the fact that there are crowd platforms already used by citizens in crisis like Ushahidi, this result suggests a lack of confidence on the integration of crowd intelligence within their practice more than a lack of confidence on technology to promote crowd intelligence. EM is a critical activity performed by professionals who have clear goals and responsibilities, so any change in their procedures has to imply an evident benefit for the organization. In a context where coordinating efforts amongst agencies is often seen as a burden [41], involving citizens might be a utopia if both decision-makers and citizens are not empowered to work together in an efficient way.

3. Citizens could do more than act as first line informants. The role of citizens as intelligent sensors and first-line informants has been studied in real cases [5-9], but as reported by the participants of the second empirical study, citizens could do more than just informing. In our experience after more than 16 years working with EM workers, mentioning citizen participation usually put them on the defensive due to two misconceptions based on fake generalizations. The first one is assuming, erroneously, that the term "citizen" refers to a homogenous crowd, where each person has exactly the same skills and knowledge and, therefore, all of them will participate in the same way. When they are reminded that VOST members are also citizens, their initial attitude changes. The second one is about what "participation" means. Many professional EM workers stick to one of two extreme options that define their position for or against citizen participation. They are quite positive when participation is seen as citizens sending or receiving information, for which they know that social networks are a resource they have to use. But when participation is perceived as citizens being proactive and taking responsibilities, most EM stakeholders adopt a negative position, since losing control of the situation could end up in damages and losses they will have to respond to. However in our study, participants were quite positive about having citizens as reactive sensors, as agents who could execute actions under supervision. Again, taking into account that not all citizens will do exactly the same tasks and that preparation is required, if you have citizens with accredited skills to act in a disaster you will use them, since EM is characterized by improvisation and the need to assume roles dynamically [13]. Social and mobile computing can contribute to speed up the location and mobilization of this kind of resources, engaging in EM other coproducers including volunteers, retired emergency workers, or citizens with skills or resources to deal with a specific hazard. The capability to integrate this information on the EMAs current information systems will make it possible to mobilize this digital social capital when a crisis happens.

\subsection{Identifying the Different Roles Citizens Can Play in EM Coproduction}

Our studies suggest that EMAs will be open to move towards a more participative EM process as far as their concerns are considered. As a first step to ideate technologies that could improve citizen coproduction in EM, the different profiles making up the dispersed crowd need to be conceptualized to understand the variety roles citizens can play when coproducing [18]. As posited by Ostrom, there are no panacea solutions [14]; there are no universal participation structures that apply everywhere and, consequently, each case has to be studied to understand how the different agents can, or will, be willing to participate. With this purpose we applied a participatory design process involving different EMAs in the identification of useful citizen skills and capabilities, which we aggregate under the concept of role.

To start with, and within the context of an industrial project aimed at deploying mobile computing applications for citizens as well as an interface for the operation center [42], we run several participatory design sessions with the Valencia Police. Valencia is a very popular touristic city in the east coast of Spain with 1.5 million residents and whose region usually suffers massive summer wildfires and 
autumn floods. In the design sessions, participation alternatives were discussed through real examples managed by the police that helped the design team to conceptualize a number of potential roles citizens could play and for which specific social computing technologies could be used. Roles are only used as way to abstract the capabilities citizens could contribute with and to ideate scenarios where technology could help to integrate such capabilities with the EMAs tools. Each person can assume one or more roles during a crisis situation or can have different roles in different situations. Five roles were identified in these sessions:

- Citizens receive information from the authorities and, therefore, we all are citizens.

- Sensors are all of the citizens who send data or information to the EMAs and, consequently, any citizen becomes a sensor whenever she contacts the EMA or uses social networks to post information about a critical situation. For instance, people sending tweets on a disaster or contacting the call center are Sensors. Whether, or under which circumstances, the organization considers these data reliable or useful is something that has to be determined in each case since as discussed in the findings of our empirical study, citizen generated content might not be reliable or precise enough to be directly used by the EMA workers.

- Trusted sensors are citizens that the EMA has identified as people whose data can be directly processed because they are reliable. They include those Sensors who can be trusted whether because the operation center has information on them (such as retired workers, volunteers or citizens who have informed in other occasions) or because they have built a reputation on social networks and therefore they can be trusted. The concept of Trusted Sensors is not new and is already implemented through the VOST groups around the world.

- Nodes are citizens that can also process data and provide more elaborate and precise information; for instance, they can evaluate the damages or the kind of assistance required. According to the experts, to become a Node you need to have accredited experience in the domain. For instance, if the operation center knows you are a citizen who has participated in drills for a specific kind of disaster (e.g. nuclear risks) and you were trained to evaluate damages, you can be granted this level.

- Agents can execute actions under the supervision of the EMA, for instance, they could lead an evacuation process. Some citizens can act as Agents, particularly if they can receive directions from the EM workers, for which mobile computing tools might be very convenient.

These five roles were discussed and further explored in a following focus group with professionals and policy-makers in EM from Madrid 112, the operation center where the different corps and agencies in charge of Madrid region collaborate to respond to emergencies. A focus group is a research technique used to discuss topics that require a broad range of opinions with a number of participants that range among five to seven [43], since the goal is to gather different perspectives more than interviewing large populations. In our study, six participants took part in the focus group, representing the police, fire service, forest service, ambulances service, and the 112 operation center. All of them had more than five years of experience in managing EM services for the whole region of Madrid, which has a population of 6.3 million residents. The goal of the focus group was to analyze whether the roles identified by a different EMA could make sense also for the participants to advance towards a coproduction process. The focus group started with a presentation about citizen participation in EM that ended up describing the five roles. Participants filled a questionnaire where each role was assessed by asking them whether the distinction between one role and the precedent was real and whether they could provide real examples of such roles from their experience as EM managers or first responders. An example of a question is shown in Figure 1. 


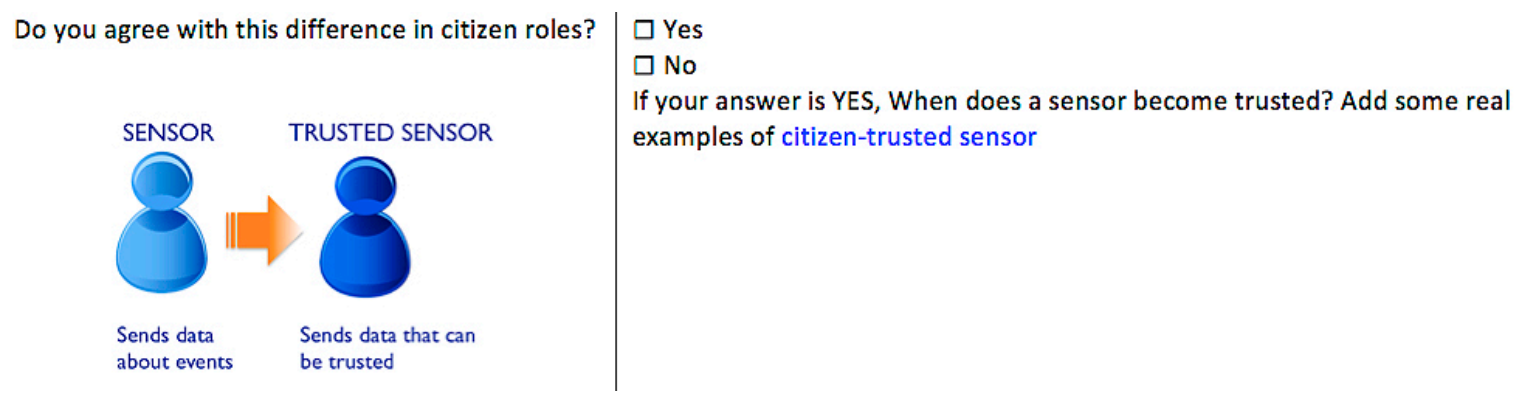

Figure 1. Example of a question in the focus group about citizen roles.

This comparison among roles and the requirements participants set to move from one role to the other made it possible to identify a potential trajectory of progressive roles that could help to understand the criteria that might be used to discriminate among them. Figure 2 illustrates the results of these discussions. This representation does not aim at representing a potential structure of participation-not even a unique or rigid path on the evolution of roles-it is just a design artifact used to gather more information on the kind of skills professional EM workers will expect from each kind of participant compared to the previous level. This simplistic representation helped to avoid the initial bias of thinking on citizens as a homogeneous crowd and focus the discussion on what makes a difference from one role to the other. For instance, analyzing the migration path from trusted sensor to node helped to establish a discussion to identify ways in which some citizens have provided valuable information, particularly in rural areas, for which participants highlighted the need to have previous experience in the kind of hazard being addressed. These trajectories illustrate potential evolutions in a coproduction process where the explicit recognition of the citizens' contributions and their interaction with the EM workers could act as an intrinsic motivation to try to exert more advanced roles and, hence, become more engaged in the EM process.

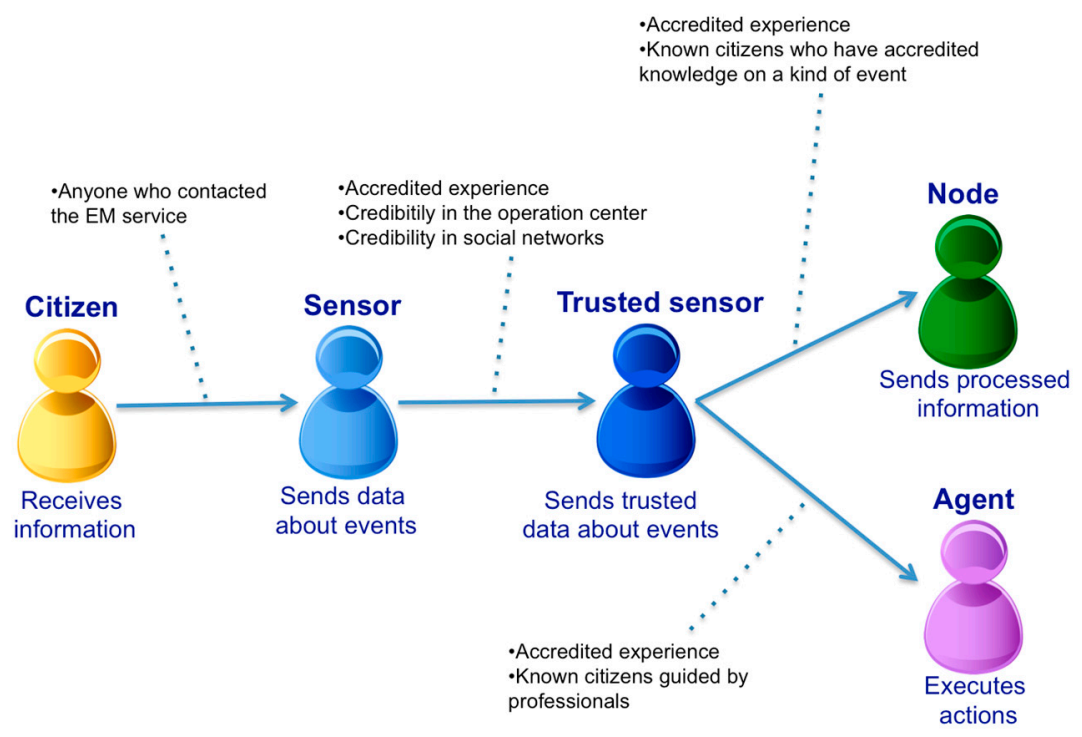

Figure 2. Understanding ways of participation through an ecology of participants.

\section{Scenarios for Technology-Mediated Citizen Participation in EM}

Based on the findings of the studies and the roles identified in the design case study, we can envision two scenarios where social and mobile computing could be used to support a coordinated action among EMAs and citizens: citizens as sources of information (that is citizens acting as sensors, trusted sensors, and nodes), and citizens acting as reactive or proactive agents able to perform specific 
activities to improve the response to an incident. To describe the scenario we make use of a design artifact called crowd capabilities [44] that provides a basic scaffold to analyze how technology can support community substantive empowerment in EM. Each crowd capability or scenario is described in terms of its Structure, Content, and Processes. The Structure defines the sources of knowledge and the means they use to provide such knowledge; the Contents are the specific organizational goals that should be met in that scenario; and the Processes are the activities that have to be executed be able to integrate the potential crowd capabilities into the organization protocols. This description is only focused on technological issues, not on the organizational and cultural aspects that should be addressed to promote citizen participation and engagment in a coproduction scenario. Thus, each scenario compiles practices in mobile and social computing design that might be taken into account to support that integration.

Scenario 1: Citizens as information providers. This scenario helps EMAs to improve their response by making use of digital social capital as an information source and it also helps to increase the transparency of public agencies. Table 2 summarises the crowd capabilities for this scenario that are discussed below.

Table 2. Scenario 1: Citizens as sensors, trusted sensors, and nodes.

\begin{tabular}{c|l}
\hline Capability Component & \multicolumn{1}{c}{ Description } \\
\hline \multirow{5}{*}{ Structure } & $\begin{array}{l}\text { Units/Roles involved; } \\
\text { Citizens working as sensors, trusted sensors, or nodes; } \\
\text { Organization: operators in the control room and workers in the field. } \\
\text { Technologies } \\
\text { Citizens: Smartphones, portable and wearable devices; } \\
\text { Organization: desktop computers, big displays, MDE platforms. }\end{array}$ \\
\hline \multirow{5}{*}{ Content } & $\begin{array}{l}\text { Receive useful data from citizens about events, particularly multimedia items, } \\
\text { to inform decision-making and provide a more efficient response; } \\
\text { Promote transparency and generate trust in citizens; } \\
\text { Empower citizens to engage them in a coproduction process. }\end{array}$ \\
& $\begin{array}{l}\text { Integrate data in the control room information system, so that operators can have } \\
\text { a holistic view of the situation combining different sources of information; } \\
\text { Provide tools to quickly and easily send useful information to the emergency } \\
\text { managers. Usefulness is defined by the organization goals and protocols } \\
\text { (use of semantic resources related to the domain of application to help in } \\
\text { categorizing information); } \\
\text { Design applications for universal usability; } \\
\text { Retrieve automatically relevant data (such as the geographical position .... ) } \\
\text { to minimize user interaction; } \\
\text { Provide ways to give feedback to participants so they know their information is } \\
\text { being processed or whether more details are needed; } \\
\text { Authenticate users when needed and comply with privacy regulations. }\end{array}$ \\
\hline
\end{tabular}

As discussed previously, and identified in our empirical studies, to integrate citizen-generated content into the EM process data timeliness, validity and quality need to be ensured $[9,13]$. It is not only a question of trust, for which authenticated trusted sensors can be used, but also a question of the quality of the information provided to support situational awareness and decision-making that only citizen-considered nodes are capable of providing. For example, in previous experiences, professional emergency workers stated that pictures and other multimedia items, like videos, are usually more informative that text descriptions which tend be imprecise and not always focused on the information that help them take decisions [32]. Filtering, data mining algorithms, and visualization can be applied to improve social media data access and interpretability $[9,40]$, but also being able to visually discriminate the credibility of the information source in map-based representations can help to take quicker decisions. The classification of roles here introduced can be used with that purpose as shown in Figure 3. As posited by Turoff et al, the tools that EM workers do not use on a daily basis will not be available on a crisis event [13], so operators needs mechanisms to classify social 
networks profiles whilst interacting with them in non critical situations. In this way they will be able to decide which ones are trusted sensors (such as other EMAs or members of VOST services) or even nodes who can provide accurate evaluations. In this way, when the crisis happens they have already categorized some citizens whose position can be added to their visual representation of the incident to facilitate the interaction with valid information sources (trusted sensors) as well as with those who can provide accurate evaluations of the situation (nodes). These interfaces should support bidirectional communication, that is, also pull strategies [23], so that operators can provide feedback on citizens generated content.

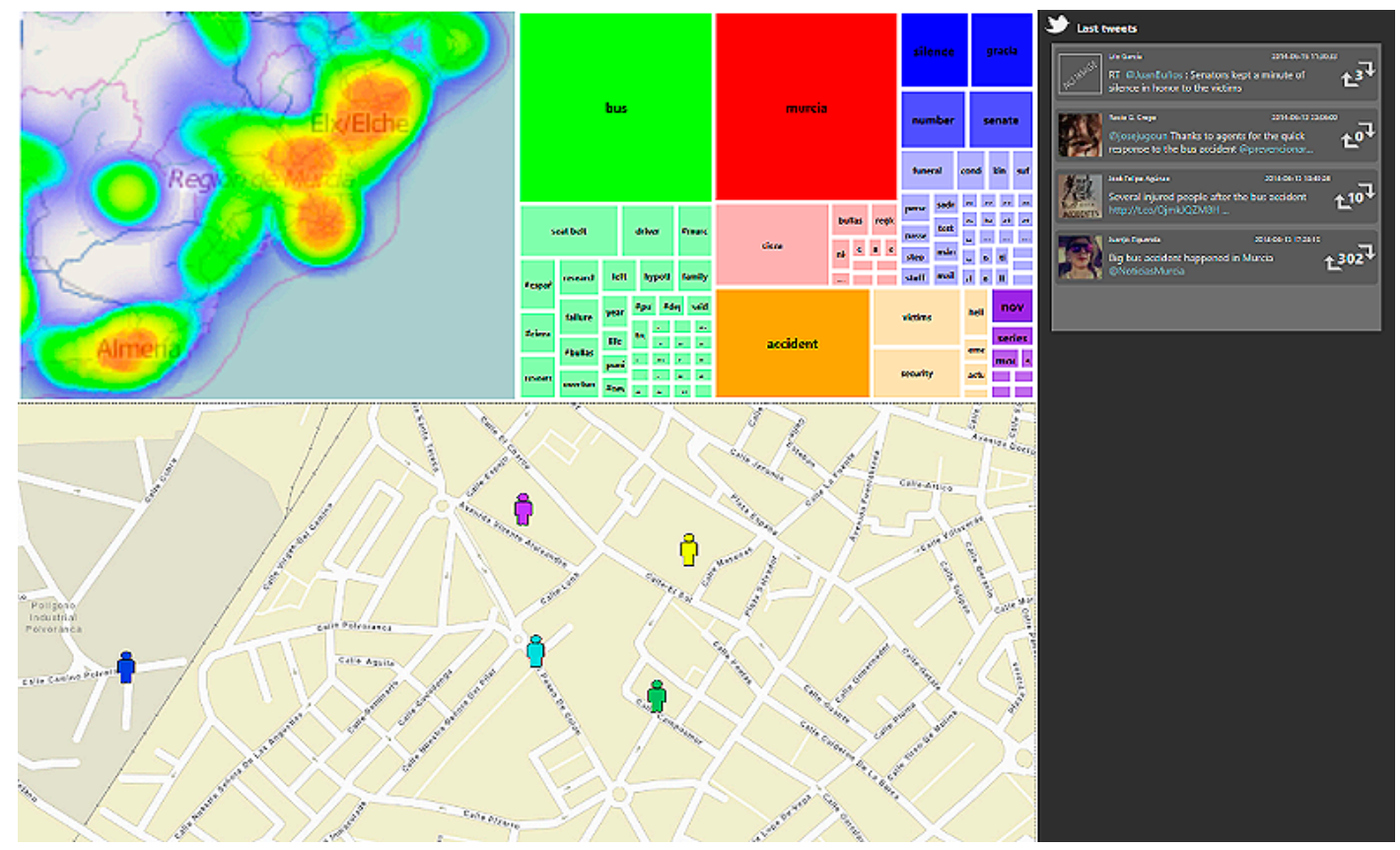

Figure 3. Displaying available citizen roles in map-based interfaces. The colored icons in the map represent different types of citizens. The operator can interact with them by selecting the icons.

Multi-display environments (MDE) can be required to cope with the varied necessities and resources of the different EMAs and professionals taking part in the EM process. Whilst desktop computers, large displays, and tabletops might be available in control rooms and can help to make sense in collaborative discussions, part of this information might also be useful for EM field workers who will use smaller displays and need different interaction options. Design has to focus on the device and on the context where the device is used to provide the right information, in the right way, in the right moment, in the right place and to the right person [45].

In order to better support the role of citizens as reactive or proactive agents, these roles might require ad hoc applications specifically designed to interact with EMAs like My112, and a $\backslash$ Android and IoS applications that supports communication among citizens and Madrid 112 or the mobile apps created for the Valencia Police described in [32]. Since citizens can use a variety of portable devices to send and receive information it is required to design the applications in order to guarantee universal usability as described by Shneiderman [46]. To facilitate their engagement in coproduction activities, the tasks citizens are expected to do should be simplified as much as possible [14], for which a minimalist interface has to be designed [47] and, whenever possible, automatic retrieval of information has to be supported.

Given the characteristics of the context where this ad hoc mobile applications will be used designers have to consider physical constraints that might difficult normal access to the information (such as noise or smoke) as well as individual constraints due to the capabilities of users as well as to the fact that they are in interacting under stress. Not only minimalist interfaces that reduce to the 
minimum the input required by the user are required $[46,47]$ but also interfaces that could be adapted to contextual or permanent user disabilities, as in [48] where ontologies are used to provide accessible alerts in different formats including text, 2D and 3D representations.

Other relevant issues related with this scenario concern security and privacy issues. On the one hand, citizens playing more reactive and proactive roles need to be authenticated so that EMAs can be sure the person they are interacting with is the one who has the capabilities to evaluate a situation or execute some kind of action. On the other side, citizens have to be aware that when using the mobile ad hoc application, their position is being monitored.

Scenario 2: Citizens as agents, delegating action to citizens. This scenario is an extension of the scenario 1, since any citizen able to act in a coordinated way with EMAs will also be able to send information. For that purpose, all the issues discussed for scenario 1 also apply to scenario 2 . The main difference relies upon the fact that in this scenario EMAs moves forward a coproduction service where coordinated action with citizens is implemented. Table 3 summarises the capabilities of this scenario.

Table 3. Scenario 2: Citizens as agents.

\begin{tabular}{c|ll}
\hline Capability Component & & \multicolumn{1}{c}{ Description } \\
\hline Structure & $\bullet$ & Scenario 1 Structure \\
\hline Content & $\bullet$ & Scenario 1 Contents \\
& $\bullet$ & $\begin{array}{l}\text { Work in partnership with citizens whose capabilities guarantee an } \\
\text { efficient response }\end{array}$ \\
\hline Process & $\bullet$ & $\begin{array}{l}\text { Scenario 1 Processes } \\
\text { Provide a quick and easy interaction mechanisms to coordinate action } \\
\end{array}$ \\
& $-\begin{array}{l}\text { among EM workers and citizens } \\
\text { Provide citizens with information on the situation and the resources } \\
\text { available for their action }\end{array}$ \\
\hline
\end{tabular}

The new scenario requires the development of ad hoc applications that can support coordinated action among EMAs and citizens acting as agents. From the point of view of the EMAs, the information and position of agents needs to be visualized in the crisis map as shown in Figure 3. In this way they can also coordinate action with other agents in the area as EM first responders usually do [49]. Interfaces for citizens should also provide this kind of information as well as information about available resources that can improve their capability to judge the situation and take action. The capability to have a "professional" perspective of the situation might help citizens realize they are part of the process, encouraging their participation in the service coproduction. For instance in [32], authors propose the use of map-based apps to understand the situation and the resources that are available, both human and physical. Simple interfaces are provided to get more information on the situation as well as to connect with the EMA. All this interaction is integrated with the EMA's information system so that it is available to understand the situation and the potential social capital that could be mobilized to cope with it.

Not only visualization is required but also agile communication channels that can speed up the interaction among citizens and the operation center. Again the interface has to be minimalist and do not overload citizens with unnecesary information neither require complex interactions. New interaction devices, like smartwatches and augmented reality glasses, will provide more opportunities for situated and usable communication. In the first case, information can be received through short text or audio messages that are usually accompanied by a vibration to attract the attention of the receiver. AR glasses are not yet a technology used by citizens in public spaces and their use raises many concerns about privacy [50], but their use cannot be discarded in the short term. This technology will make it possible to augment physical spaces with additional information about how to act or which other agents are in the area to coordinate action, without moving the focus of attention of the agent to an external device. 


\section{Conclusions}

Citizens are valuable assets who can contribute with their skills and social resources to build more efficient public services, as the research on coproduction has shown in many different domains, from police, to health or education $[3,18,19,27,28]$. Emergency managament is not different from other public services and relying upon citizens will make organization not less, but more, efficient, as well as contribute to promote more connected and resilient communities. Social and mobile computing applications can contribute to take profit from an existing social digital capital but for this to be possible technologies have to be designed along with EM decision-makers and workers to also understand their needs and fears. In this paper we discussed through a design case study how we involved EM professionals in discussions about the roles citizens could play. These roles were used to avoid the generalization of the concept of citizen as a homogenous entity instead of a heterogoenous crowd and, thus, force EM workers and decisions-makers to think about capabilities that some citizens could contribute with to an EM process envisioned as a coproduction system. Analyzing the roles enabled discussions on the characteristics that could make EM professionals to categorize a citizen within a specific role and how citizens could acquire more advanced roles with higher capabilties to take decisions and act. We also discussed the technical implications of the scenarios where these roles were involved, providing both information and skills. Deploying technological tools to exercise these roles might promote a higher engagement with the community the EM workers that might encourage citizens to get ready to assume more responsiblities in the process. Coproduction is also learning experience, where citizens get a deeper knowledge, awareness, and understanding on the work of professionals, and public services understand the strenghts and vulnerabilties of the communities and how they can contribute and not only get help.

From a technical point of view, further work should focus on other phases of the EM process particularly in the preparation phase, in order to establish a continuous relationship with citizen both to guarantee they will be able to use the tools when a crisis happens and also to engage them in the process and promote the generation of digital social capital on EM. Gamification and pervasive computing might be technologies that could help to engage citizens in rewarding experiences but the reasons to coproduce are varied, and as stated by Alford there is not a unique recipe that works in all cases [18]. Whilst, in some cultures, personal or social recognition might work, in other cases coproducers will be more active if negative incentives are used.

Acknowledgments: This work is supported by the project emerCien grant funded by the Spanish Ministry of Economy and Competitivity (TIN2012-09687) and by the grant PRX15/00184 funded by the Spanish Ministry of Education. Authors would like to thank to the City Council of Richmond and Madrid 112 for their participation in the organization of the empirical workshops and to all the EM workers who participated with their comments and views.

Author Contributions: Paloma Díaz and Ignacio Aedo performed the empirical studies and focus group. The three authors worked together on the study of coproduction and its application to emergency management. John M. Carroll contributed to establish the theoretical framework of the research.

Conflicts of Interest: The authors declare no conflict of interest.

\section{References}

1. Mandarano, L.; Meenar, M.; Steins, C. Building social capital in the digital age of civic engagement. J. Plann. Lit. 2010, 25, 123-135. [CrossRef]

2. Endsley, M.R.; Jones, D.G. Designing for Situational Awareness: An Approach to User-Centered Design, 2nd ed.; CRC Press, Taylor \& Francis Group: Boca Raton, FL, USA; London, UK; New York, NY, USA, 2003.

3. Linders, D. From e-government to we-government: Defining a typology for citizen coproduction in the age of social media. Government Inf. Q. 2012, 29, 446-454. [CrossRef]

4. Stallings, R.; Quarantelli, E.L. Emergent citizen groups and emergency management. Public Adm. Rev. 1985, 45, 93-100. [CrossRef] 
5. Palen, L.; Anderson, K.M.; Mark, G.; Martin, J.; Sicker, D.; Palmer, M.; Grunwald, D. A vision for technology-mediated support for public participation and assistance in mass emergencies and disasters. In Proceedings of the 2010 ACM-BCS Visions of Computer Science Conference (ACM-BCS '10); British Computer Society: Swinton, UK, 2010.

6. Vieweg, S.; Hughes, A.L.; Starbird, K.; Palen, L. Microblogging during two natural hazards events: What twitter may contribute to situational awareness. In Proceedings of the SIGCHI Conference on Human Factors in Computing Systems, Atlanta, GA, USA, 10-15 April 2010; pp. 1079-1088.

7. White, C.M. Social Media, Crisis, Communication, and Emergency Management: Leveraging Web 2.0 Technologies; CRC Press: Boca Raton, FL, USA, 2012.

8. Jaeger, P.T.; Shneiderman, B.; Fleischmann, K.R.; Preece, J.; Qu, Y.; Wu, F.P. Community response grids: E-government, social networks, and effective emergency response. Telecommun. Policy 2007, 31, 592-604. [CrossRef]

9. Ludwig, T.; Reuter, C.; Pipek, V. Social Haystack: Dynamic Quality Assessment of Citizen-Generated Content during Emergencies. ACM Trans. Comput.-Hum. Interact. 2015, 22, 17. [CrossRef]

10. Goodchild, M.F. Citizens as sensors: The world of volunteered geography. GeoJournal 2007, 69, $211-221$. [CrossRef]

11. Boulos, M.N.K.; Resch, B.; Crowley, D.N.; Breslin, J.G.; Sohn, G.; Burtner, R.; Chuang, K.Y.S. Crowdsourcing, citizen sensing and sensor web technologies for public and environmental health surveillance and crisis management: Trends, OGC standards and application examples. Int. J. Health Geogr. 2011, 10, 1.

12. Carver, L.; Turoff, M. Human-computer interaction: The human and computer as a team in emergency management information systems. Commun. ACM 2007, 50, 33-38. [CrossRef]

13. Turoff, M.; Chumer, M.; Van de Walle, B.; Yao, X. The design of a dynamic emergency response management information system (DERMIS). J. Inf. Technol. Theor. Appl. 2004, 5, 1.

14. Ostrom, E. Crossing the great divide: Coproduction, synergy, and development. World Dev. 1996, 24, 1073-1087. [CrossRef]

15. Petak, W.J. Emergency management: A challenge for public administration. Publ. Adm. Rev. 1985, 45, 3-7. [CrossRef]

16. Waugh, W.L.; Streib, G. Collaboration and leadership for effective emergency management. Publ. Adm. Rev. 2006, 66, 131-140. [CrossRef]

17. Dynes, R.R. Social Capital Dealing with Community Emergencies. Homeland Secur. Affairs 2006, 2, 1-26.

18. Alford, J. The multiple facets of co-production: Building on the work of Elinor Ostrom. Publ. Manag. Rev. 2014, 16, 299-316. [CrossRef]

19. Boyle, D.; Harris, M. The challenge of co-production. In London: New Economics Foundation; NESTA: London, UK, 2009.

20. Jacobs, J. The death and Life of Great American Cities; Vintage Books: New York, NY, USA, 1961.

21. Goolsby, R. Social media as crisis platform: The future of community maps/crisis maps. ACM Trans. Intell. Syst. Technol. 2010, 1, 7. [CrossRef]

22. Benkler, Y. Political Freedom part 2: Emergence of the networked public sphere. In Wealth Networks: How Social Production Transforms Markets and Freedom; Yale University Press: New Haven, CT, USA, 2006.

23. Mergel, I. Social media adoption: Toward a representative, responsive or interactive government? In Proceedings of the 15th Annual International Conference on Digital Government Research, New York, NY, USA, 18-21 June 2014; pp. 163-170.

24. Meier, P. Self-Organized Crisis Response to \#BostonMarathon Attack. Available online: http:/ /irevolution. net/2013/04/16/bostonmarathon-attack/ (accessed on 2 August 2016).

25. FEMA. Principles of Emergency Management; FEMA Report: Washington, DC, USA, 2007.

26. Norris, F.H.; Stevens, S.P.; Pfefferbaum, B.; Wyche, K.F.; Pfefferbaum, R.L. Community resilience as a metaphor, theory, set of capacities, and strategy for disaster readiness. Am. J. Community Psychol. 2008, 41, 127-150. [CrossRef] [PubMed]

27. Aldrich, D.P. The power of people: Social capital's role in recovery from the 1995 Kobe earthquake. Nat. Hazard. 2011, 56, 595-611. [CrossRef]

28. Murphy, B. Locating social capital in resilient community-level emergency management. Nat. Hazard. 2007, 41, 297-315. [CrossRef] 
29. Putnam, R.D.; Leonardi, R.; Nanetti, R.Y. Making Democracy Work: Civic Traditions in Modern Italy; Princeton university press: Princeton, NJ, USA, 1994.

30. Putnam, R. The prosperous community: Social capital and public life. Am. Prospect 1993, 13, 35-42.

31. Fischer, G.; Piccino, A.; Ye, Y. The ecology of participants in co-evolving socio-technical environments. Eng. Interact. Syst. 2008, 5247, 279-286.

32. Romano, M.; Onorati, T.; Díaz, P.; Aedo, I. Improving emergency response: Citizens performing actions. In Proceedings of the 11th International ISCRAM Conference, University Park, PA, USA, 18-21 May 2014; pp. 170-174.

33. Wulf, V.; Rohde, M.; Pipek, V.; Stevens, G. Engaging with practices: Design case studies as a research framework in CSCW. In Proceeding of Computer Supported Cooperative Work, Hangzhou, China, 19-23 March 2011; pp. 502-512.

34. Diaz, P.; Aedo, I.; Arias, R.; Díez, D. Towards Emergency 2.0: Social media and Civil Engagement in Emergency Management. In Proceedings of the Workshop on Large Scale Ideation and Deliberation Systems, Marseille, France, 29 May 2012.

35. Herranz, S.; Díaz, P.; Díez, D.; Aedo, I. Studying social technologies and communities of volunteers in emergency management. In Proceeding of the 6th International Conference on Communities and Technologies, Munich, Germany, 29 June-2 July 2013; pp. 140-148.

36. Díaz, P.; Aedo, I.; Herranz, S. Citizen participation and social technologies: Exploring the perspective of emergency organizations. Inf. Syst. Crisis Response Manag. Mediterr. Ctries. 2014, 196, 85-97.

37. Fugate, C. Understanding the Power of Social Media as a Communication Tool in the Aftermath of Disasters, Address to the United States Senate Committee on Homeland Sec. and Gov. Affairs, ad hoc Subcommittee on Disaster Recovery and Intergovernmental, May 2005; Committee on Homeland Security and Governmental Affairs: Washington, DC, USA, 2005.

38. Arnstein, S.R. A Ladder of Citizen Participation. JAIP 1969, 35, 216-224. [CrossRef]

39. Oliver-Smith, A.; Hoffman, S.M. Theorizing Disasters: Nature, Power and Culture (Catastrophe and Culture: The Anthropology of Disaster); School of American Research Press: Santa Fe, NM, USA, 2002.

40. Onorati, T.; Díaz, P. Semantic Visualization of Twitter Usage in Emergency and Crisis Situations. Inf. Syst. Crisis Response Manag. Mediterr. Ctries. 2015, 233, 3-14.

41. Aedo, I.; Díaz, P.; Carroll, J.M.; Convertino, G.; Rosson, M.B. End-user oriented strategies to facilitate multi-organizational adoption of emergency management information systems. Inf. Process. Manag. 2010, 46, 11-21. [CrossRef]

42. Onorati, T.; Aedo, I.; Romano, M.; Díaz, P. EmergenSYS: Mobile technologies as support for emergency management. Smart Organ. Smart Artifacts 2014, 7, 37-45.

43. Lazar, H.; Feng, J.H.; Hochheiser, H. Research Methods in Human-Computer Interaction; John Wiley Sons: West Sussex, UK, 2010.

44. Prpic, J.; Shukla, P. The Theory of Crowd Capital. In Proceedings of the Hawaii International Conference on Systems Sciences 46, Maui, HI, USA, 7-10 January 2013.

45. Fischer, G. Context-Aware Systems: The 'Right' Information, at the 'Right' Time, in the 'Right' Place, in the 'Right' Way, to the 'Right' Person. In Proceedings of the Working Conference on Advanced Visual Interfaces; Tortora, G., Leviadi, S., Tucci, M., Eds.; ACM: New York, NY, USA, 2012; pp. 287-294.

46. Shneiderman, B. Universal usability: Pushing human-computer interaction research to empower every citizen. Commun. ACM 2000, 43, 84-91. [CrossRef]

47. Carroll, J.M. The Nurnberg Funnel: Designing Minimalist Instruction for Practical Computer Skill; MIT Press: Cambridge, MA, USA, 1990.

48. Onorati, T.; Malizia, A.; Díaz, P.; Aedo, I. Modeling an ontology on accessible evacuation routes for emergencies. Expert Syst. Appl. 2014, 41, 7124-7134. [CrossRef]

49. Catarci, T.; de Leoni, M.; Marrella, A.; Mecella, M.; Salvatore, B.; Vetere, G.; Truong, H.L. Pervasive software environments for supporting disaster responses. Internet Comput. 2008, 12, 26-37. [CrossRef]

50. Roesner, F.; Kohno, T.; Molnar, D. Security and privacy for augmented reality systems. Commun. ACM 2014, 57, 88-96. [CrossRef] 